\title{
Performance of a Suspension Bridge with Active Vibration Dampers
}

\author{
Anatolij Konovalov ${ }^{1}$, and Marina Pustovalova ${ }^{1, *}$ \\ ${ }^{1}$ Northern (Arctic) Federal University named after M.V. Lomonosov, Arhangelsk, Russia
}

\begin{abstract}
Suspended structures that are used extensively in construction of motorway and pedestrian bridges allow bridging wide spans without having to install intermediate supports. Being less stiff in comparison to girder and arch bridges, suspension bridges require their dynamic properties to be controlled $[1,2]$. This is a vital task when it comes to suspension bridges. Several engineering arrangements are available to control the dynamic properties of the structures [3]. This paper addresses the use of active dampers [4] installed on the tops of the towers as the means to control vibrations of a suspension bridge. To this end, a planar 3D model of suspension bridge was built using ANSYS software. The authors compared stress-strain behavior and dynamic properties of the models with and without active vibration dampers. In contrast to the initial model, the model of a bridge equipped with active dampers exhibits less displacement in all cross-sections. Thus, the displacements are reduced 1.7 times in the middle of the central span of suspended stiffening truss; 2.7 times in the middle of the end span; and displacements of the top of the bridge tower are 1.6 times less. The modal analysis has shown that in the model with active dampers the frequency of transverse vibrations at the tower tops has increased 1.9 times, while vertical vibrations have increased within $23 \%$. Under maximum applied overpressure in the active damper, torsional vibrations of the structure have increased 2.4 times as compared to the initial model. The results obtained by the authors allow for the conclusion that active dampers are useful tools for controlling the dynamic properties of a suspension bridge.
\end{abstract}

\section{Design Model}

The structural design model of a suspension bridge used in this study was tied to the location of a proposed bridge across the Northern Dvina River in Arkhangelsk [3]. Planar 3D finite element model was generated in ANSYS software suite. It was a full-size model with $200 \mathrm{~m}$ end spans and $450 \mathrm{~m}$ middle span. The tower was $90 \mathrm{~m}$ high, of which 30 meters were the height of the bridge, and 60 meters were the height of the tower from the stiffening truss to the top of the tower.

*Corresponding author: m.pustovalova@narfu.ru 
Each tower comprises a box-shaped section having the stiffness of $\mathrm{EA}_{\mathrm{twr}}=1,907 \mathrm{E}+5$ $\mathrm{MN}, \mathrm{EI}_{\text {maxtwr }}=1,7 \mathrm{E}+6 \mathrm{MN}^{*} \mathrm{~m}^{2}, \mathrm{EI}_{\text {mintwr }}=5,8 \mathrm{E}+5 \mathrm{MN} * \mathrm{~m}^{2}$, and rigid connection with the ground.

Steel stiffening truss comprised a closed bock-shaped structure [2] with the stiffness of $\mathrm{EA}_{\mathrm{tr}}=5,4 \mathrm{E}+5 \mathrm{MN}, \mathrm{EI}_{\text {maxtr }}=5 \mathrm{E}+7 \mathrm{MN}^{*} \mathrm{~m}^{2}, \mathrm{EI}_{\text {mintr }}=2 \mathrm{E}+6 \mathrm{MN} * \mathrm{~m}^{2}$. On one side, the stiffening truss rested on the ground with a hinged immovable support, and a hinged moveable support was used on the other side.

The main suspension cable was assumed to have the stiffness of $\mathrm{EA}_{\mathrm{cbl}}=2,1 \mathrm{E}+5 \mathrm{MN}$, and was fixed on independent anchors separately from the truss. The main suspension cable was a solid structure and had no rigid ties with the towers. Stay cables were assumed with the stiffness of $\mathrm{EA}_{\text {stay }}=5,3 \mathrm{E}+4 \mathrm{MN}$, and had their hinged ends adjoin the main cable and the truss. The stay cables of the bridge were arranged crosswise at a $10 \mathrm{~m}$ interval in the middle third of the central span, and vertically at the same interval in the rest of the model [3] (Figure 1).

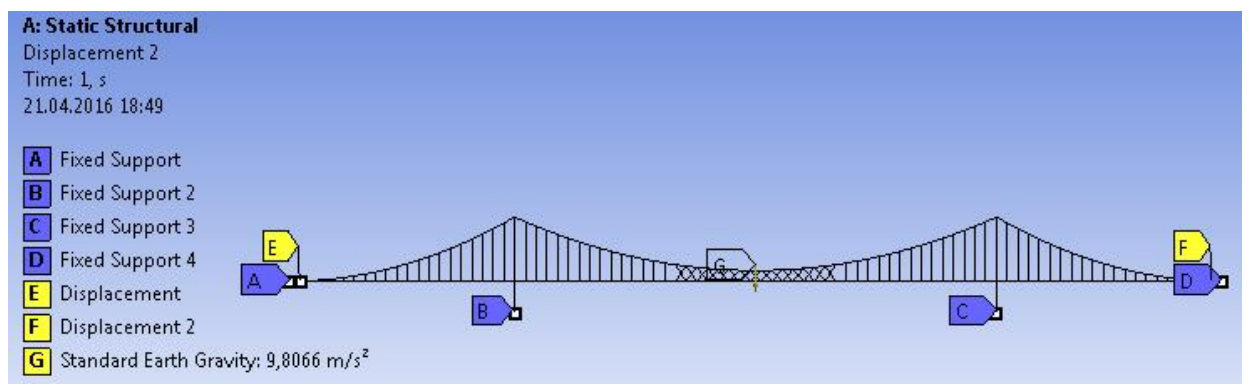

Fig. 1. The Initial Model of the Bridge

\section{Active Fluid Damper}

Special engineering arrangements are used to dampen vibrations of high-rise structures resulting from transient effects. A distinction is made between passive and active dynamic dampers. Numerical simulations [4] have proven an active damper to be more efficient than a passive mechanical damper for construction of high-rise structures in seismically hazardous areas.

An active damper is a fluid vibrations dampening device. The operating principle consists in generating an alternating reactive force by alternately opening or closing the opposite valves on the vessel to relief excess pressure of service fluid. The device is described in operation [4]. See the operating principle schematic diagram on Figure 2.

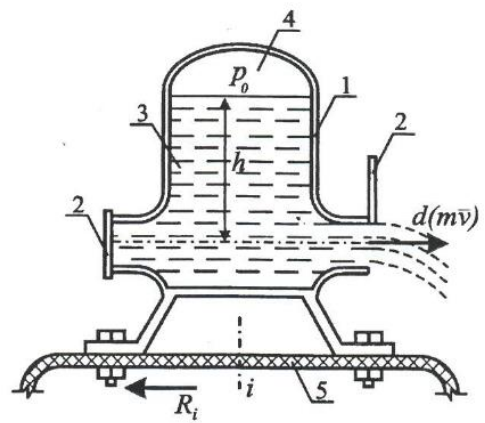

Fig. 2. Schematic drawing showing operation of an active fluid damper: 1- vessel; 2 - valve; 3 service fluid; 4 - pressurized gas; 5 - protected structure. 
The parameters of an active fluid damper used for numerical simulation are described below. The initial weight of the damper was assumed equal to $17 \%$ of the weight of the entire structure. The area of the valves' opening was $100 \mathrm{~cm}^{2}$. The opening/closing time was $0.02 \mathrm{~s}$. Several cases of operation of active dampers with variations of overpressure in the damper vessel were analyzed.

In the case simulating the use of the damper for controlling vibrations of the suspension bridge structure, the active dampers were located at the tops of the towers.

\section{Stress-Strain Analysis}

The comparative analysis of stress-strain state of the two models was carried out: the model without structural modifications and the model with active dampers on the tops of the bridge towers. The obtained data were summarized in Table 1 .

The results obtained by numerical simulation show that in terms of the distribution of forces, the performance of the model of a suspension bridge with active dampers on the tops of the towers to be close to the model where no special engineering arrangements were used.

Fairly noticeable changes were observed in displacements of the structural elements. In contrast to the initial model, the model with active dampers on the top of the towers exhibits less displacements in the structural elements: by $28 \%$ in the middle of the central span; by $64 \%$ in the middle of the end spans, and by $38 \%$ at the top of the bridge towers.

Table 1. Longitudinal Forces and Displacements of the Compared Models

\begin{tabular}{|c|c|c|}
\hline Parameter & $\begin{array}{c}\text { Initial } \\
\text { Model }\end{array}$ & $\begin{array}{c}\text { Active } \\
\text { Dampers } \\
\text { Model }\end{array}$ \\
\hline $\begin{array}{c}\text { Longitudinal forces in the } \\
\text { main suspension cable, } \\
\times 10^{8} \mathrm{~N}\end{array}$ & 1.741 & 1.66 \\
\hline $\begin{array}{c}\text { Longitudinal forces in the } \\
\text { stiffening truss in the mid } \\
\text { span, } \times 10^{8} \mathrm{~N}\end{array}$ & 0.430 & 0.348 \\
\hline $\begin{array}{c}\text { Longitudinal forces in the } \\
\text { stiffening truss near the } \\
\text { tower, } \times 10^{8} \mathrm{~N}\end{array}$ & -0.291 & -0.287 \\
\hline $\begin{array}{c}\text { Deflection in the center of } \\
\text { the central span, } \mathrm{m}\end{array}$ & 2.030 & 1.174 \\
\hline $\begin{array}{c}\text { Deflection in the center of } \\
\text { the end span, } \mathrm{m}\end{array}$ & 0.724 & 0.264 \\
\hline $\begin{array}{c}\text { Displacement of the tower } \\
\text { top, } \mathrm{m}\end{array}$ & 0.457 & 0.285 \\
\hline
\end{tabular}

\subsection{The Effects of Overpressure in the Vessel of Active Fluid Damper on the Performance of Suspension Bridge Structure}

We have reviewed three cases of overpressure. An increase of overpressure results in the increase of the alternating reactive force, in other words, it increases the stiffness of the bridge tower.

The first case simulated maximum overpressure, while in the second and third case it was respectively two and four times lower. As one can see on the plots (Figure 3), a change 
of overpressure in the active damper vessel has almost no effect (varies within $2 \%$ ) on the distribution and magnitude of longitudinal forces in the suspension bridge structure.

With decrease in overpressure of gas, the displacements of some structural elements increase by $15 \%$ in the middle of the central span, by $44 \%$ in the end spans and by $23 \%$ at the top of the towers (Figure 4).

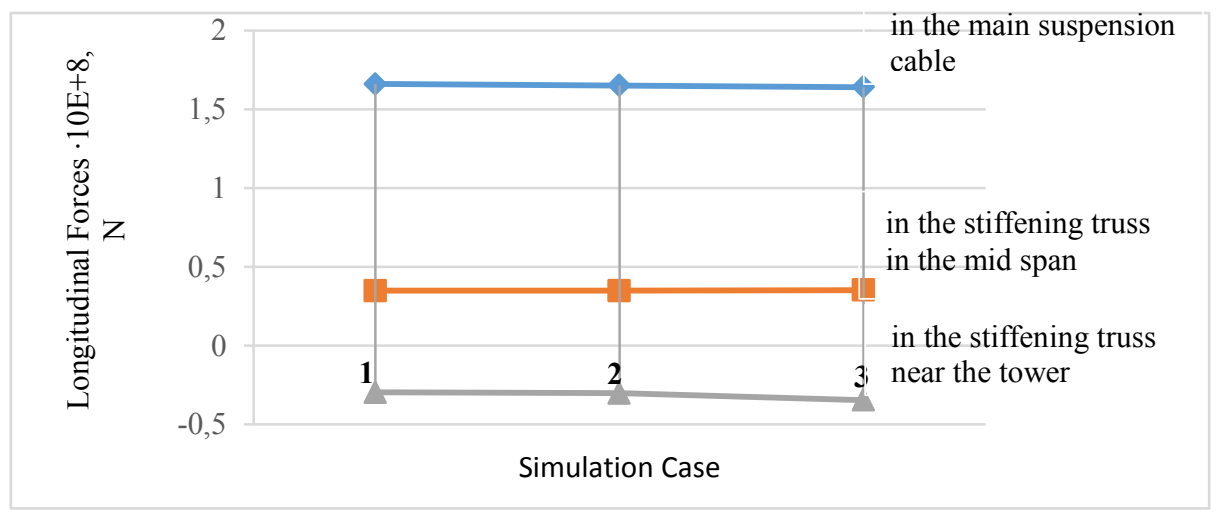

Fig. 3. The Effects of Gas Overpressure in the Active Damper Vessel on Longitudinal Forces: Case 1 - Maximum Pressure; 3 - Minimum Pressure;

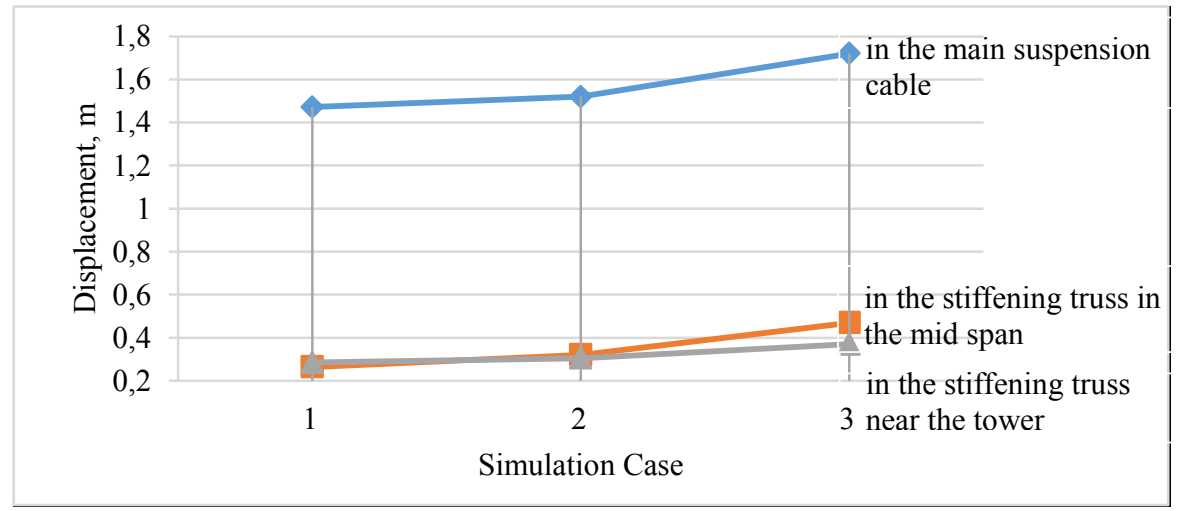

Fig. 4. The Effects of Gas Overpressure in the Active Damper Vessel on Displacements: Case 1 Maximum Pressure; 3 - Minimum Pressure

\section{Modal Analysis}

The use of ANSYS system allows displaying a wide range of natural vibrations and identifying the effects of the structural design scheme on the behavior of the model. The outcome of determining the fundamental frequencies of natural vibrations in the initial model and in the model supplied with active dampers is shown in Table 2. 
Table 2. The Frequencies of Natural Vibrations in the Compared Models

\begin{tabular}{|c|c|c|}
\hline Parameter & Initial Model & $\begin{array}{c}\text { Active } \\
\text { Dampers } \\
\text { Model }\end{array}$ \\
\hline $\begin{array}{c}\text { Transverse vibrations } \\
\text { frequency, Hz }\end{array}$ & 0.162 & 0.309 \\
\hline $\begin{array}{c}\text { Vertical vibrations } \\
\text { frequency, Hz }\end{array}$ & 0.272 & 0.3094 \\
\hline $\begin{array}{c}\text { Torsional vibrations } \\
\text { frequency, Hz }\end{array}$ & 0.251 & 0.448 \\
\hline
\end{tabular}

The modal analysis has shown that the fundamental frequency of vibrations in the suspension bridge model supplied with active dampers installed on the tower tops varies by values and directions of vibrations as compared to the initial model. The first mode shape represents transverse vibrations of the system just as in the initial model (Figure 5), and the frequency of vibrations is 1.9 times higher.

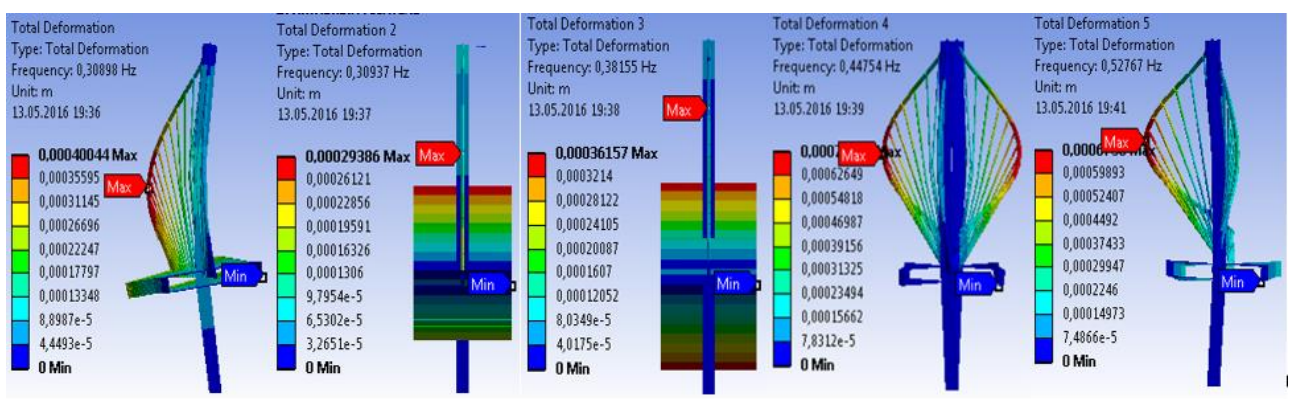

Fig. 5. Modal Analysis of Suspension Bridge with Active Dampers on the Tower Tops (Mode Shapes $1-5)$

The second mode shape, vertical vibrations, is also consistent with the initial model: the frequency of vibrations observed in the model with active dampers is $12 \%$ higher. The forth mode shape and the following mode shapes represent torsional vibrations of different directions (Figure 5). In the model supplied with an active damper, the frequency of torsional vibrations is 1.8 times higher than in the initial model.

The frequency of natural vibrations of a suspended bridge equipped with an active damper shows only moderate decrease in response to the reduction of gas overpressure in the damper vessel: $9 \%$ for transverse vibrations, $10 \%$ for vertical vibrations, and $24 \%$ for torsional vibrations (Figure 6). 


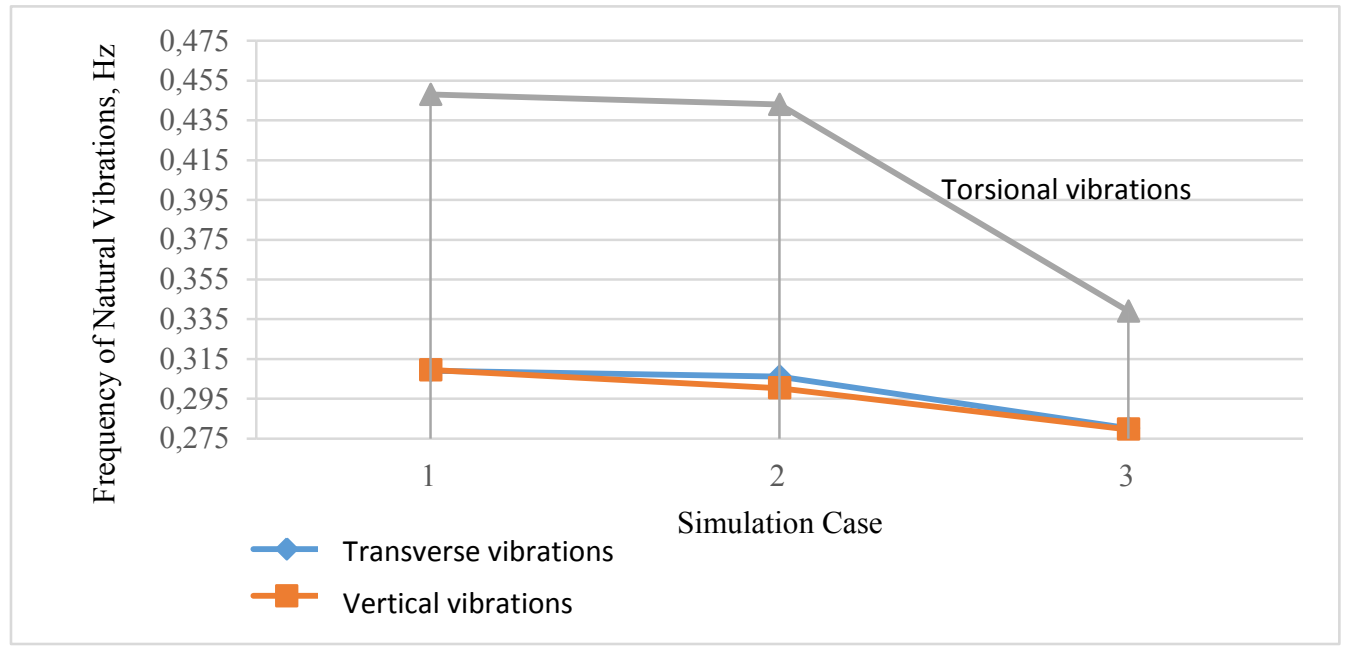

Fig. 6. The Effects of Variations in Overpressure of Gas in the Active Damper Vessel on the Frequencies of Natural Vibrations: Case 1 - Maximum Pressure; Case 3 - Minimum Pressure

The mode shapes of vibrations for the first simulation case shown on Figure 7 are in exact accordance with the direction of vibrations in the initial model.

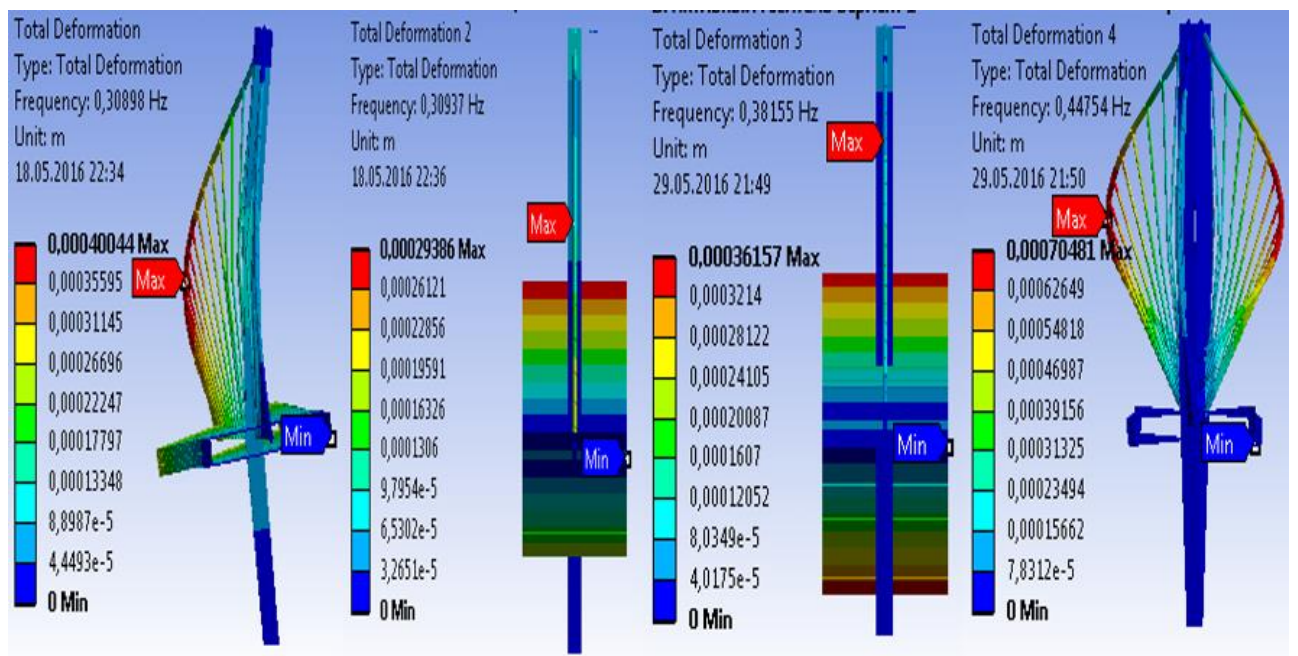

Fig. 7. The First Four Mode Shapes of Vibrations of the Structure with Active Dampers, Case 1

When a four-fold decrease in the overpressure of gas occurs in the active damper vessel, the mode shapes of vibrations change places. Any further decrease of overpressure results in the decrease of vibration frequencies, but no further change in their direction occurs.

\section{Aerodynamic Stability Analysis}

A change in dynamic properties of the structure has an effect on its aerodynamic stability. The term of aerodynamic stability is written as [5]:

$$
v_{c r} \gg v_{\text {wind }} \text { or } v_{c r}>1,5 v_{\text {wind }}
$$


where $v_{\text {wind }}$ is the design velocity of the wind, i.e. the maximum possible speed of wind than can occur in the given geographic area of the bridge construction (normally $v_{\text {wind }}=$ $25-35 \mathrm{~m} / \mathrm{s}$ ); and 1.5 is a safety factor.

The practice of structural analysis for suspension bridges uses different methods and criteria for evaluation of aerodynamic stability, which are based on the frequency of natural vibration of the bridge structures.

A.A. Petropavlovskiy describes the relationship between the flow velocity $(v)$, typical normalized size $(h)$ of the structure in the direction normal to the flow, and the frequency $\left(\Theta_{w}\right)$ of the Karman's vortex shedding: [6, p.183]

$$
S_{H}=\Theta_{w} \cdot \frac{h}{v}
$$

where $\Theta_{w}$ is the circular frequency of the Karman's vortex;

$S_{N}$ is the Strouhal number, which depends on the shape of the structure. For bridges $S_{N}=0.12 \div 0,18$, the $S_{N}$ was assumed to equal 0.15 .

For wind resonance, the aerodynamic stability by critical velocity is determined using the following formula:

$$
v_{c r}=w \cdot \frac{2 \pi \cdot \sqrt{h_{B} \cdot B}}{S_{N}}
$$

where $h_{B}$ is the height of stiffening truss, m;

$B$ is the breadth of the bridge, $\mathrm{m}$;

$w$ is the frequency of natural vibrations of the structure, $\mathrm{Hz}$.

The results of the calculation of wind resonance critical velocities obtained by the formula (3) for the models analyzed in this paper are listed in Table 3.

Table 3. Calculated Wind Resonance Critical Velocities

\begin{tabular}{|l|c|c|c|}
\hline \multicolumn{1}{|c|}{ Parameters } & \multicolumn{3}{|c|}{ Vibration Frequency $\mathbf{w}, \mathbf{H z}$} \\
\hline Critical Velocity $\boldsymbol{v}_{\boldsymbol{c r}}, \mathbf{m} / \mathbf{s}$ \\
\hline Initial model & $\frac{0.162}{74.3}$ & $\frac{0.272}{124.7}$ & $\frac{0.251}{115.1}$ \\
\hline $\begin{array}{l}\text { Model with active } \\
\text { dampers }\end{array}$ & $\frac{0.309}{141.7}$ & $\frac{0.309}{141.9}$ & $\frac{0.448}{205.5}$ \\
\hline
\end{tabular}

\section{Conclusion}

The modal analysis has shown that in the model with active dampers the frequency of transverse vibrations at the tower tops has increased 1.9 times, while vertical vibrations have increased within $23 \%$. Under the maximum overpressure in the active damper considered in the simulation, the frequency of torsional vibrations has increased 2.4 times versus the initial model. The results obtained by the authors allow for the conclusion that active dampers are useful tools for controlling the dynamic properties of a suspension bridge.

\section{References}

1. N.P. Abovskij, Driven designs, SAU NDS. KISI, 125 (1995) 
2. A.S. Dorogan, Cable-stayed bridges of Increased stiffness. Str. Mech. and An. of Constr. E 4 (2011)

3. A. Konovalov, M. Pustovalova, 00083 E 26th RSP (2017)

4. A.I.Shein, D.A. Shmelev, Str. Mech. and An. of Constr. (2014)

5. A.A. Baranovskij, Bridges of large spans. Design of suspended and cable-stayed bridges (PGUPS, 2005)

6. A.A. Petropavlovskij, Cable-stayed bridges (Moscow, 1985) 